\title{
IKLIM ORGANISASI DAN KOMITMEN ORGANISASI DOSEN UNIVERSITAS NEGERI JAKARTA
}

\author{
Mauna* \\ Amanda Tiara Sari** \\ * Fakultas Pendidikan Psikologi, Universitas Negeri Jakarta \\ ** Fakultas Pendidikan Psikologi, Universitas Negeri Jakarta
}

DOI: https://doi.org/10.21009/JPPP.052.03

\author{
Alamat Korespondensi: \\ mauna@unj.ac.id \\ amandatiarasari@gmail.com
}

\begin{abstract}
This study aims to examine empirically whether there is influence between psychological climate to organizational commitment. The subject were 221 lecturer of State University of Jakarta (UNJ) selecting using incidental sampling technique. This type of research is a quantitative research, data collection techniques using research data obtained through survey instruments/questionnaire adaption from previous researchers. Instruments made have been tested for validity and reliability, and belonging to the reliable criteria. Research hypothesis testing was performed using linear regression analysis of the predictors, with the psychological climate as a predictor variable. The analysis shows a correlation coefficient of 0,000 , less than the significance level (0.05). This value is interpreted that there are significant psychological climate to organizational commitment. The coefficient of determination shows rxy2 value of 0.301 , meaning that there is a $30,1 \%$ variance tendency of psychological climate on. So this research indicates that the lecturer will indicate the optimal organizational commitment if it has high psychological climate.
\end{abstract}

Keywords:

organizational commitment, psychological climate, lecturer of State University of Jakarta (UNJ)

\section{Pendahuluan}

Pendidikan merupakan faktor utama dalam pembentukan bangsa. Pendidikan memegang peranan penting untuk meningkatkan dan mengembangkan kualitas sumber daya manusia suatu bangsa. Menurut UU No.20 Tahun 2003 pendidikan merupakan usaha sadar dan terencana untuk mewujudkan suasana belajar dan proses pembelajaran agar peserta didik secara aktif mengembangkan potensi dirinya untuk memiliki kekuatan spiritual keagamaan, pengendalian diri, kepribadian, kecerdasan, akhlak mulia, serta keterampilan yang diperlukan untuk dirinya, masyarakat, bangsa dan negara.

Pemerintah yang sudah mulai menyadari pentingnya pendidikan mengambil langkah- lang- kah serius dalam menangani sistem pendidikan. Sistem pendidikan yang baik diharapkan dapat mempersiapkan generasi penerus bangsa yang berkualitas. Segala perbaikan dilakukan oleh pemerintah dalam berbagai aspek antara lain sistem pembelajaran, tenaga pengajar maupun fasilitas. Hal ini dilakukan pada keseluruhan tingkat pendidikan yang terdiri dari tingkat Sekolah Dasar (SD), Sekolah Menengah Pertama (SMP), Sekolah Menengah Atas (SMA) serta Perguruan Tinggi.

Perguruan tinggi sebagai salah satu lembaga pendidikan formal mempunyai wewenang dan tanggung jawab mempersiapkan generasi penerus bangsa pada tingkat akhir. Perguruan tinggi menjalankan perannya dengan mengacu pada tridarma 
perguruan tinggi yaitu mampu menyelenggarakan pendidikan, melakukan penelitian, dan melakukan pengabdian masyarakat (UU RI No.12 Tahun 2012). Perguruan tinggi dibagi menjadi perguruan tinggi negeri dan perguruan tinggi swasta.

Faktanya perguruan tinggi negeri yang berada di DKI Jakarta hanya tiga yaitu Universitas Negeri Jakarta (UNJ), Universitas Indonesia (UI) dan Universitas Islam Negeri Jakarta (UIN Jakarta). Sedangkan untuk perguruan tinggi swasta terdapat lebih banyak dibanding perguruan tinggi negeri di DKI Jakarta antara lain Universitas Tarumanegara, Universitas Trisakti, Universitas Bakrie, Universitas Paramadina dan sebagainya.

Tidak dapat dipungkiri bahwa perguruan tinggi negeri memiliki peran dan posisi strategis dalam pencapaian tujuan untuk mewujudkan sumber daya manusia yang berkualitas langsung di bawah arahan pemerintah. Untuk itu, keberadaan manusia sebagai sumber daya sangat penting karena sumber daya manusia dapat menunjang kualitas perguruan tinggi tersebut melalui karya, bakat, kreativitas, dorongan dan peran nyata. Salah satu instrumen sumber daya manusia dalam perguruan tinggi yaitu tenaga pengajar perguruan tinggi atau dosen.

Dosen merupakan instrumen sumber daya manusia yang sangat menentukan keberhasilan proses pendidikan di perguruan tinggi karena dosen yang mengajar dan mendidik mahasiswa secara langsung. Menurut Peraturan Pemerintah No.60 Tahun 1999 dosen adalah seorang yang berdasarkan pendidikan dan keahliannya diangkat oleh penyelenggara perguruan tinggi dengan tugas utama mengajar pada perguruan tinggi. Banyak pakar dan pemerhati mutu perguruan tinggi mengemukakan bahwa dosen merupakan salah satu komponen vital penggerak utama sebagai faktor kesuksesan dari sistem pendidikan dan pengajaran yang akhirnya akan memengaruhi produktivitas proses pembelajaran dan produktivitas lembaga.

Sampai saat ini pekerjaan sebagai dosen merupakan bidang pekerjaan yang masih kurang diminati dibandingkan pekerjaan lain. Sesuai data Pangkalan Data Pendidikan Tinggi Kementerian Riset, Teknologi, dan Pendidikan Tinggi (PDDIKTI KEMENRISTEK) pada Mei Tahun 2017 hanya terdapat sebanyak 71.420 dosen dengan sekitar 2.057.085 mahasiswa aktif di seluruh perguruan tinggi negeri se-Indonesia.

Kurangnya tenaga pengajar perguruan tinggi tersebut diikuti dengan masalah pengkaderan dosen, terutama permasalahan mengenai banyaknya jumlah dosen yang kurang berkomitmen dengan profesinya sebagai dosen. Masalah lainnya untuk kebanyakan perguruan tinggi negeri yaitu cukup banyaknya dosen yang melakukan kegiatan di luar kampus (moonlighting) demi mencukupi kebutuhan finansial karena gaji sebagai dosen dirasakan kurang memadai.

Salah satu masalah yang disebabkan kurangnya komitmen dosen terlihat pada kehadirannya di dalam kelas. Menurut penelitian yang dilakukan oleh Annisa (2016) rata-rata jam kehadiran dosen pada salah satu perguruan tinggi $X$ adalah 19,5 jam/minggu sedangkan kewajiban dosen sesuai peraturan SK Dekan No.20 Tahun 2006 pada perguruan tinggi $\mathrm{X}$ tersebut minimal kehadiran dosen di dalam kelas adalah $25 \mathrm{jam} /$ minggu.

Permasalahan tersebut juga terjadi di Universitas Negeri Jakarta terlihat pada kurangnya kehadiran para dosen Universitas Negeri Jakarta. Hal ini didapatkan dari data presensi sidik jari yang direkap secara rutin tiap harinya oleh Biro Umum dan Kepegawaian (BUK) Universitas Negeri Jakarta. Sesuai dengan data yang diberikan oleh BUK kepada peneliti pada bulan April 2017, tingkat presensi atau kehadiran dosen Universitas Negeri Jakarta hanya sebesar 55,019\% untuk periode Mei 2016 sampai desember 2016. Sedangkan sisanya yaitu sebesar $41,591 \%$ tidak hadir atau tidak melakukan presensi sidik jari, dinas di luar kota sebesar 3,136\%, dan izin sebesar $0,254 \%$.

Tidak dapat dipungkuri hal ini cenderung merugikan mahasiswa dan proses pembelajaran dikarenakan ketidakhadiran dosen di perguruan tinggi dapat membuat mahasiswa tidak menerima haknya dalam mendapatkan informasi dan pengetahuan yang diharapkan secara langsung dari dosen ketika sedang dalam proses pembelajaran maupun secara tidak langsung bisa melalui diskusi di luar kelas. Kurangnya kehadiran dosen di perguruan tinggi juga menyulitkan bagi birokrat perguruan tinggi untuk dapat menjalankan langkah-langkah untuk lebih memajukan Universitas Negeri Jakarta. 
Berdasarkan studi pendahuluan, ada beberapa faktor yang memengaruhi tetap aktifnya dosen di kampus. Faktor-faktor tersebut yaitu minat yang tinggi untuk mengajar, meneliti, dan memberikan pelayanan pada masyarakat; usia yang sudah terlalu lanjut untuk pindah pekerjaan; merasa tidak memiliki alternatif pekerjaan lain; atau karena adanya komitmen yang tinggi pada perguruan tinggi (Liche, 2006). Agar dapat menjalankan berbagai perannya dengan baik, dosen diharapkan untuk menjadi dosen berkualitas dan memiliki komitmen yang tinggi pada perguruan tinggi. Hal ini bertujuan agar perguruan tinggi dapat menyusun berbagai rencana pengembangan dengan lebih mantap dan berkesinambungan.

Sayangnya di Indonesia belum banyak yang melihat pentingnya peran komitmen organisasi dosen pada perguruan tinggi terhadap peningkatan mutu dan perkembangan perguruan tinggi tersebut. Meskipun sudah ada sanksi yang diberikan oleh perguruan tinggi terhadap dosen yang tidak banyak terlibat dalam kegiatan di kampus termasuk kegiatan pendidikan dan pengajaran, tetapi tampaknya sanksi tersebut tidak membuat jera beberapa individu. Melihat hal ini, sangat disayangkan karena hal ini dapat mengganggu proses pencapaian tujuan perguruan tinggi.

Secara umum, komitmen organisasi adalah keterikatan karyawan pada organisasi dimana karyawan bekerja. Ada tiga komponen komitmen organisasi yaitu komitmen afektif, komitmen rasional, dan komitmen normatif (Allen dan Meyer, 1990). Pertama, komitmen afektif terdiri dari karakteristik pribadi, karatkteristik jabatan, pengalaman kerja (rasa aman dalam organisasi dan merasakan kompeten menjalankan peran), serta karakteristik struktural. Kedua, komitmen rasional terdiri dari besarnya jumlah investasi atau taruhan sampingan individu pada organisasi, dan persepsi atas kurangnya alternatif pekerjaan lain. Ketiga, komitmen normatif terdiri dari pengalaman individu saat masuk dalam organisasi serta pengalaman sosialisasi selama berada di dalam organisasi.

Salah satu faktor yang memiliki hubungan dengan komitmen organisasi dosen pada organisasi adalah kepribadian dosen yaitu kesesuaian antara kepribadian dosen dengan pekerjaannya (person-job-fit) dapat memengaruhi komitmen dosen terhadap organisasinya (Steers, 1977).
Selain faktor kepribadian, ada kemungkinan faktor lainnya yang memengaruhi tinggi atau rendahnya komitmen organisasi dosen yaitu faktor lingkungan.

Pada penelitian ini, faktor lingkungan yang diteliti adalah iklim psikologis. Iklim psikologis (psychological climate) merupakan rangkuman deskriptif dosen terhadap pengalaman mereka dalam organisasi (Jones dan James, 1979). Penelitian Biswas (2009) menunjukkan bahwa iklim psikologis yang positif mengarah pada pemberdayaan seorang individu. Hal ini tercermin dalam perubahan sikap positif terhadap pelaksanaan pekerjaan mereka. Iklim psikologis yang kondusif juga memungkinkan individu memperluas kegiatan dan meningkatkan dedikasi mereka terhadap organisasi. Selain itu, Sahin (2011) menemukan indikasi hubungan antara persepsi iklim psikologis, komitmen afektif dan turn over intention (kecenderungan untuk keluar) pada 238 pekerja dari beberapa perusahaan layanan keamanan di Turki.

Brown \& Leigh (1996) mengemukakan bahwa iklim psikologis yang didasarkan pada bagaimana karyawan memandang aspek lingkungan organisasi dan mempersepsikan lingkungan tersebut berkaitan dengan kesejahteraan individu. Iklim psikologis terdiri dari supportive management, role clarity, self-expression, recognition, contribution, dan challenge. Masing-masing dimensi tersebut merupakan indikator apakah karyawan menerima lingkungan organisasi sebagai suatu yang menyenangkan dan nyaman (Kahn, 1990 dan Brown dan Leigh, 1996).

Sesuai penelitian yang telah dilakukan oleh Liche (2006) terdapat hasil bahwa karakteristik supportive management merupakan indikator yang paling kuat bagi iklim psikologis. Hal ini berarti bahwa tingkah laku pimpinan fakultas dan perguruan tinggi memegang peran penting dalam membentuk, mempertahankan, dan meningkatkan komitmen dosen pada perguruan tinggi tersebut. Tingkah laku pimpinan perguruan tinggi ini dapat ditampilkan dalam bentuk memberikan kepercayaan, dukungan, dan penghargaan kepada dosendosen ketika menjalankan pekerjaan yang bernilai penting bagi fakultas dan perguruan tinggi; memberikan kesempatan kepada dosen untuk mendiskusikan masalah pribadi atau akademik yang dihadapi dosen; mengatur pembagian kerja yang 
adil bagi semua dosen; hati-hati dalam menangani masalah yang dihadapi fakultas dan perguruan tinggi; serta konsisten dalam menjalankan kebijakan yang telah ditetapkan.

Berdasarkan penjelasan di atas, dapat disimpulkan bahwa iklim psikologis merupakan salah satu faktor yang mungkin dapat memengaruhi komitmen organisasi. Untuk itu peneliti tertarik untuk meneliti mengenai pengaruh iklim psikologis terhadap komitmen organisasi pada dosen salah satu perguruan tinggi negeri di DKI Jakarta yaitu Universitas Negeri Jakarta. Peneliti berpendapat bahwa iklim psikologis dapat memengaruhi tinggi atau rendahnya komitmen organisasi dosen Universitas Negeri Jakarta.

\section{Metode Penelitian}

Tipe penelitian ini adalah penelitian kuantitatif dengan pendekatan penelitian korelasional. Populasi dalam penelitian ini adalah Dosen Universitas Negeri Jakarta. Subjek penelitian ini memiliki karakteristik sebagai berikut dosen tetap Universitas Negeri Jakarta dan sudah memiliki masa kerja minimal 2 tahun. Teknik sampling yang dilakukan dalam penelitian ini adalah non probability sampling. Teknik non probalitas yang digunakan adalah jenis incidental sampling. Jumlah sampel dalam penelitian ini adalah sebanyak 221 orang. Pada penelitian ini, pengumpulan data dilakukan dengan menggunakan kuesioner (self report) sebagai alat pengumpul data. Kuesioner untuk variabel komitmen organisasi menggunakan alat ukur Organizational Commitment Questionaire (OCQ) yang dikembangkan dari dasar teori Allen dan Meyer dan diadaptasi oleh Prof. Liche Seniati dari Fakultas Psikologi, Universitas Indonesia. Instrumen ini berjumlah 18 pernyataan. Sedangkan untuk nstrumen iklim psikologis yang digunakan dalam penelitian yaitu Psychological Climate Questionaire (PCQ) ini dikembangkan dari teori Brown dan Leigh yang diadaptasi pula oleh Prof. Liche Seniati dari
Fakultas Psikologi, Universitas Indonesia. Instrumen ini berjumlah 19 pernyataan.

Metode penelitian berisi jenis penelitian, metode penelitian yang digunakan, pedekatan penelitian yang digunakan (kuantitatif/kualitatif), variabel penelitian, jenis data penelitian, responden penelitian (populasi dan sampel), teknik pengumpulan data, instrumen penelitian yang digunakan, dan teknik analisis data.

Metode penelitian disajikan menggunakan font Times New Roman 12pts, spasi 1,0.

\section{Hasil dan Diskusi}

Sebelum instrumen digunakan terlebih dahulu dilakukan proses uji validitas dan reliabilitas. Untuk instrumen OCQ memiliki reliabilitas 0,833 dan instrumen PCQ memiliki reliabilitas 0,849, keduanya termasuk kedalam kategori reliabel. Instrumen OCQ memiliki 3 item yang gugur sedangkan PCQ memiliki 2 item yang gugur.

Penelitian dilakukan di Universitas Negeri Jakarta yang terbagi menjadi beberapa kampus yaitu Kampus A Rawamangun, Kampus B Velodrome, Kampus D Halimun dan Kampus E Setiabudi. Penyeberan instrumen dilakukan dengan memasuki masing-masing sebanyak 61 program studi. Proses penyeberan instrumen dibantu oleh pihak program studi baik koordinator program studi maupun staf tata usaha program studi.

Data mengenai komitmen organisasi didapatkan dari instrumen OCQ yang terdiri dari 18 item dan diisi langsung oleh subjek penelitian. Dari hasil penelitian dan pengolahan data menggunakan aplikasi Winstep diperoleh nilai minimum yaitu -1,02 dan nilai maksimum sebesar 6,41. Skor rata-rata (mean) komitmen organisasi adalah 1,2267 dengan standar deviasi 1,09098.

Skor komitmen organisasi yang didapat dari penelitian ini dikategorikan menjadi dua kategori yaitu tinggi dan rendah. Penentuan kategori dilakukan berdasarkan mean normatif dari data. Dibawah ini disajikan dalam bentuk tabel.

Tabel 1. Kategori Skor Komitmen Organisasi

\begin{tabular}{ccc}
\hline Kriteria & Jumlah Subjek & Persentase \\
\hline Rendah $(<1,2267)$ & 130 & 58,8 \\
\hline Tinggi $(>1,2267)$ & 91 & 41,2 \\
\hline
\end{tabular}


Berdasarkan tabel di atas dapat diketahui bahwa terdapat 130 subjek dengan presentase 58,8\% termasuk dalam kategori memiliki komitmen organisasi rendah dan 91 subjek dengan persentase 41,2\% memiliki komitmen organisasi tinggi. Sehingga secara umum dapat dilihat bahwa komitmen organisasi dosen Universitas Negeri Jakarta masih dalam kategori rendah. Hal ini terbukti dari penelitian yang dilakukan menunjukkan hasil bahwa lebih banyak subjek yang memiliki komitmen organisasi yang rendah.
Sedangkan data mengenai iklim psikologis diperoleh dengan pengisian instrumen PCQ dengan 19 item. Data tersebut kemudian diolah menggunakan aplikasi Winstep diperoleh skor minimum adalah -1,60 dan skor maksimum adalah 8,17 . Skor rata-rata (mean) iklim psikologis adalah 1,9541 dengan standar deviasi yaitu 1,39309 .

Data iklim psikologis dikategorikan menjadi dua yaitu tinggi dan rendah. Penentuan kategori dilakukan berdasarkan mean normatif dari data. Dibawah ini disajikan dalam bentuk tabel.

Tabel 2. Kategori Skor Iklim Psikologis

\begin{tabular}{ccc}
\hline Kriteria & Jumlah Subjek & Persentase \\
\hline Rendah $(<1,9541)$ & 111 & 50,2 \\
\hline Tinggi $(>1,9541)$ & 110 & 49,8 \\
\hline
\end{tabular}

Berdasarkan tabel di atas dapat diketahui bahwa terdapat 111 subjek dengan presentase $50,2 \%$ termasuk dalam kategori memiliki iklim psikologis rendah dan 110 subjek dengan presentase $49,8 \%$ memiliki iklim psikologis tinggi.

Berdasarkan hasil pengujian dengan analisis regresi sederhana diperoleh hasil bahwa terdapat pengaruh signifikan oleh iklim psikologis terhadap komitmen organisasi. Hal ini dapat dilihat dari nilai $\mathrm{F}=94.429, \mathrm{p}=0,000<0,05$. Hasil pengujian hipotesis dengan menggunakan regresi linear memperoleh nilai konstanta variabel komitmen organisasi 0,387 dan koefiesien regresi iklim psikologis sebesar 0,430. Persamaan regresi berdasarkan data yang ada yaitu: $\mathrm{Y}=0,387+$ $0,430 X$. Hal ini berarti dalam hubungan antara iklim psikologis dan komitmen organisasi pada dosen Universitas Negeri Jakarta terjadi hubungan dengan arah yang positif.

Dari hasil data yang diperoleh juga dapat disimpulkan bahwa iklim psikologis memiliki pengaruh yang signifikan terhadap komitmen organisasi. Besar kontribusi iklim psikologis terhadap komitmen organisasi diketahui dengan melihat perolehan nilai $R$ Square yaitu 0,301 atau sebesar $30,1 \%$. Hal tersebut menunjukkan bahwa ada faktor lain sebesar $69,9 \%$ yang dapat memengaruhi komitmen organisasi pada dosen Universitas Negeri Jakarta.

Hasil penelitian ini mendukung temuan pada penelitian terdahulu. Beberapa penelitian terda- hulu yang meneliti mengenai pengaruh antara iklim psikologis terhadap komitmen organisasi juga menunjukkan bahwa terdapat pengaruh positif dari iklim psikologis terhadap komitmen organisasi, tetapi kebanyakan penelitian terdahulu meneliti karyawan suatu perusahaan dan belum ditemukan oleh peneliti yang menggunakan subjek dosen atau pengajar.

Aliffiadi (2016) menjelaskan bahwa memang ada hubungan signifikan antara iklim psikologis dengan komitmen organisasi dan terdapat pengaruh positif iklim psikologis dengan komitmen organisasi pada pegawai dinas sosial Kota Malang. Pandangan dan pengalaman individu yang baik terhadap lingkungannya dan memicu tumbuh dan meningkatnya komitmen organisasi individu tersebut. Individu menjadi lebih rela memberikan kontribusi lebih dan tetap berada dalam organisasi tersebut.

Selain penelitian tersebut, adapula penelitian lainnya yang meneliti mengenai pengaruh iklim psikologis terhadap affective commitment. Biswas (2009) menjelaskan bahwa terdapat hubungan signifikan antara iklim psikologis dan komitmen afektif. Komitmen afektif tersebut juga dapat dijadikan variabel mediator antara iklim psikologis dengan keterlibatan kerja. Penelitian dilakukan pada subjek yang berasal dari sektor perusahaan manufaktur dan organisasi sektor jasa. Dalam penelitian ini dijelaskan bahwa semakin tinggi iklim psikologis maka semakin tinggi komitmen afektif dan keterlibatan kerja seseorang. 
Robbins (2001) menyatakan bahwa komitmen organisasi sebagai salah satu perilaku kerja yang merefleksikan perasaan seseorang (suka atau tidak suka) dengan organisasi tempat ia bekerja sedangkan iklim psikologis merupakan rangkuman deskriptif individu terhadap pengalamannya selama berada didalam suatu organisasi. Berdasarkan pendapat tersebut dapat disimpulkan, apabila dosen mempersepsikan pengalaman di lingkungan kerjanya dengan baik dan merasa senang, maka komitmen organisasinya akan meningkat.

Berdasarkan hasil penelitian ini, dimana komitmen organisasi dosen Universitas Negeri Jakarta berada dalam kategori yang rendah. Hal ini cukup disayangkan karena jika komitmen organisasi dosen tinggi besar kemungkinan dapat menunjung keberhasilan di Universitas Negeri Jakarta dan dunia pendidikan tingkat akhir. Oleh karena itu, agar komitmen organisasi dosen Universitas Negeri Jakarta dapat meningkat diharapkan perguruan tinggi dapat meningkatkannya melalui salah satunya yaitu peningkatan iklim psikologis yang telah terbukti mempunyai kontribusi pengaruh kepada komitmen organisasi.

\section{Kesimpulan}

Berdasarkan data yang diperoleh dari penelitian ini diketahui bahwa jumlah dosen Universitas Negeri Jakarta yang memiliki iklim psikologis rendah lebih banyak daripada dosen Universitas Negeri Jakarta yang memiliki iklim psikologis tinggi. Sedangkan komitmen organisasi berdasarkan penelitian ini juga lebih banyak pada kategori rendah. Hasil penelitian menunjukan bahwa terdapat pengaruh yang signifikan antara iklim psikologis terhadap komitmen organisasi pada dosen Universitas Negeri Jakarta. Pengaruh iklim psikologis terhadap terhadap komitmen organisasi dosen memiliki hubungan yang positif.

\section{Daftar Pustaka}

Allen, N. J., \& Meyer, J. P. (1990). The Measurement and Antecedents of Affective, Continuance, and Normative Commitment to the Organization. Journal of Occupational Psychology, 1-18.
Biswas, S. (2009). Affective Commitment as A Mediator Between Psychological Climate and Job Involvement. Journal of Management \& Public Policy, 15 (1), 22-32.

Brown, S. P., \& Leigh, T. W. (1996). A New Look At Psychological Climate And Its Relationship To Job Involvement, Effort, And Performance. Journal of Applied Psychology, 81, 358-368.

Firmanto, A. (2016). Pengaruh Iklim Psikologis terhadap Komitmen Organisasi pada Pegawai Dinas Sosial Kota Malang. Malang: Fakultas Psikologi Universitas Islam Negeri Maulana Malik Ibrahim Malang.

Jones, A. P., \& L.R. James. (1979). Psychological Climate: Dimensions and Relationship of Individual and Aggregated Work Environment Perceptions. Organizational Behavior and Human Performance, 23, 201250.

Kahn, W. A., (1990). Psychological Conditions of Personal Engagement and Disengagement at Work. Academy of Management Journal, 33, 692-724.

Pangkalan Data Pendidikan Tinggi Kementerian Riset, Teknologi, dan Pendidikan Tinggi (PDDIKTI KEMENRISTEK). Jumlah dosen se-Indonesia. Diakses dari https:// forlap.ristekdikti.go.id/dosen

Peraturan Pemerintah Republik Indonesia Nomor 60 Tahun 1999 Tentang Pendidikan Tinggi.

Rani, A. M. (2016). Analisis Faktor Kehadiran Dosen di Universitas X. Spectrum Industri, 14, 217-230.

Robbins, S. P. (2001). Organizational Behavior (9th ed.). Upper addle River New Jersey 07458 : Prentice Hall International. 
Sahin, F. (2011). Affective Commitment as A Mediator of the Relationship Between Psychological Climate and Turnover Intention. World Applied Sciences Journal, 144, 523-530.

Seniati, A. N. L. (2006). Pengaruh Masa Kerja, Trait Kepribadian, Kepuasan Kerja, dan Iklim Psikologis terhadap Komitmen Dosen pada Universitas Indonesia. Disertasi Psikologi. Depok: Fakultas Psikologi Universitas Indonesia.
Steers, R.M. (1977). Antecedents and outcomes of organizational commitment. Administrative Science Quarterly, 22, 46- 56.

Undang-Undang Republik Indonesia Nomor 12 Tahun 2012 Tentang Pendidikan Tinggi. Undang-Undang Republik Indonesia Nomor 20 Tahun 2003 Tentang Sistem Pendidikan Nasional. 